\title{
BIOREFINERY DONE RIGHT
}

\author{
MICHAEL LUGO-PIMENTEL ${ }^{1}$, IULIAN ZOLTAN BOBOESCU ${ }^{1}$, JEAN-BAPTISTE BEIGBEDER ${ }^{1}$, \\ XAVIER DURET ${ }^{2}$, FREDERIK JOHANNES WOLFAARDT $^{1}$, THIERRY GHISLAIN $^{1}$ \& \\ JEAN-MICHEL LAVOIE ${ }^{1}$ \\ ${ }^{1}$ Biomass Technology Laboratory, Sherbrooke, Québec, Canada. \\ ${ }^{2}$ RéSolve Énergie, Canada.
}

\begin{abstract}
Following the COP21 conference in Paris, most of the world's industrialized countries, as well as emerging markets, pledged to reduce or stabilize their greenhouse gas (GHG) emissions in light of increasing concerns regarding climate change [1]. The necessity to decrease GHG emissions will have implications on the consumption patterns of different types of energies around the world. Apart from the obvious need to replace part of the increasing fossil fuel consumption in transportation (including road, rail, air and sea), there is a growing demand in other sectors as well, such as for electricity production, heating and cooling.

Many opportunities are being investigated to address some of the issues related to this green energy transition, including the increased harnessing of alternative energy sources such as wind, solar, hydro, geothermal and biomass. Despite varying potential for each of the mentioned energy sources to help replace or supplement fossil fuels, only biomass currently has the potential to address most of these needs without requiring significant changes to existing energy distribution networks. For example, biomass can be burnt to generate combined heat and power, but it can also be used as a source of carbon to produce biofuels. In the latter case, biofuels such as ethanol could be blended into the existing fuel pool as well as distributed and utilized in engines without requiring significant modifications to the existing chain of distribution. This adaptiveness is not necessarily the case when considering electric vehicles (EV), although they are also of crucial importance towards collectively reducing GHG emissions.

This manuscript will review the Biorefinery Done Right-concept, developed by the company RéSolve Énergie in close collaboration with the Biomass Technology Laboratory. This simple feedstock-agnostic technology allows conversion of any type of residual biomass (including but not limited to softwood bark) to three-types of biofuels. The first objective is to take advantage of the carbohydrate content in the biomass through hydrolysis of the constitutive hemicellulose and cellulose. The fermentable sugars are then converted to ethanol, achieved without any constraints, since the RéSolve process generates a hydrolysate with very low inhibitor levels. The lignin recovered from the process is essentially unmodified lignin and after washing, it is pelletized. Pellets, containing the most energetic components of the lignocellulosic biomass, can provide up to $26 \mathrm{GJ} /$ tonne. Finally, the non-fermentable sugars (C5), as well as the lignin that does not comply with Grade A lignin characteristics, are predigested for utilization in a classical biomethanation system. Hence, through this approach, $100 \%$ of the carbon from the biomass is converted into commercial products, which at this point are all related to the energy market. Keywords: Advanced biofuels, biorefinery, lignin valorization.
\end{abstract}

\section{INTRODUCTION}

For decades, the main feedstocks for fuel grade ethanol on the market have been corn (or other grain crops), sugar cane, sorghum, sugar beet and other cultures that also have a strong link with the food industry [2]. With an increasing global demand for transportation fuel, whether for personal vehicles or for heavy transportation (trucks, rail, ships, airplanes), there has been an increased focus on alternative fuel sources in anticipation for the time when fossil fuels become more difficult and expensive to acquire [3].

In addition, there is a growing understanding and awareness of the greenhouse gas (GHG) emissions related to different fuel types [4], and concerns regarding the related climate change effects [5]. At the same time, the global renewable-energy market, and the infrastructure required to support this, have been expanding. Technologies such as photovoltaic panels, wind 
farms and geothermal energy are already less expensive and more efficient in most parts of the world than fossil-based ones, with some estimates suggesting that all mainstream renewable energy sources will become more competitive by 2020 [6]. These technologies can act as additive sources for other large-scale and already economical technologies such as hydropower, which increases the ability to replace at least part of the growing fossil-based fuel demand. However, there are currently two main disadvantages to green electricity. Firstly, most of the technologies that are being implemented at large scale are still struggling with the long-term storage and on-demand availability of generated power. Secondly, although these renewable-energy technologies can provide a direct pathway to the generation of heating, cooling and production of electricity, its adaptation for the transportation sector is more challenging. It requires a paradigm shift from the current system based on liquid fuel, such as gasoline or diesel. Although there is increasing interest in and adoption of EV's in the private, personal vehicle market, the expansion to commercial, heavy transportation vehicles has been slower than anticipated [7] and facing significant challenges [8]. For some specific cases (such as air transport), a fully integrated electric or hydrogen-based system is still decades away.

Considering this, biomass remains one of the only sources of energy that has the potential of being renewable while being adaptable enough to different possible utilizations in the energy sector. Through combined heat and power systems (CHP), biomass can be used to simultaneously produce electricity and heat [9] or used independently to produce either one of those two options. Additionally, biomass can be used as a source of carbon for the production of liquid fuels. Ethanol has for decades been considered a potential combustion fuel for vehicles, even by pioneers of this industry, such as Henry Ford [10]. One of the first and still most popular carbohydrate sources used to produce ethanol is starch extracted from corn grains. Besides corn, various other options have been considered and used at large scale for the production of ethanol such as sugar cane, wheat, sorghum, sugar beet, etc. [2]. However, a growing world population and competing demand for utilizing these feedstocks for either fuel or food, have been constraining the expansion of the first-generation ethanol $(1 \mathrm{G})$ industry. Consequently, for a few decades now, other feedstocks have been envisioned for biofuel production, such as lignocellulosic biomass. The latter is being produced by both the forestry industry and the agricultural industry. The original link between $1 \mathrm{G}$ and second-generation (2G) ethanol is related to the fact that both rely on glucose, with $1 \mathrm{G}$ ethanol sourcing its glucose from starch, while $2 \mathrm{G}$ ethanol is sourcing its glucose from cellulose and hemicellulose. This approach, generally referred to as the 'bio' approach, would allow linking $2 \mathrm{G}$ with $1 \mathrm{G}$ through sugar production. Hence, if a technology allowing the economical production of glucose from lignocellulosic biomass can be found, the resulting sugars could be further processed in a $1 \mathrm{G}$ distillery, thus efficiently utilizing already-existing infrastructure [11]. To this purpose, cellulose must be isolated from the lignocellulosic matrix, then hydrolyzed to glucose in order to be fermented downstream to ethyl alcohol. This concept is often constrained by three significant technological challenges.

First, the isolation of the carbohydrate matrix from lignocellulosic biomass (cellulose and hemicelluloses) is often expensive, relying on actual pulping technologies such as Kraft, soda or thermomechanical pulping processes, or other emerging technologies such as Organosolv and steam processes [12]. Once cellulose is isolated from the lignocellulosic matrix, it can be hydrolyzed to glucose using a catalyst. The latter can be a biocatalyst (such as an enzyme cocktail), which has the advantage of being very selective and efficient while simultaneously being able to operate at lower temperatures [13]. Classical homogeneous and heterogeneous catalysts have also been utilized, including inorganic acids, of which sulfuric acid and hydrochloric acid are 
the most popular [14]. Other inorganic acids such as nitric and phosphoric acids have also been considered [15], as well as solid catalysts such as carbon catalysts [16]. Most of these catalysts were shown to be efficient for cellulose hydrolysis at different ranges and conditions. However, there is a challenge in scaling-up these technologies in that the end-product, ethanol, is a low value commodity. Hence there is a very low margin for the production of sugar, requiring recovery of most, if not all of the catalyst, in order to make the process economically viable.

The second significant challenge, that materializes once the production of glucose and ethanol has been ensured, is the residual lignin. Lignin is the second-most abundant component in biomass after cellulose, and the only natural polymer with a superabundance of aromatic compounds. It is composed of phenylpropane units and is also known for being very recalcitrant [17]-[19]. In literature, many pathways have been considered for the utilization of lignin, including depolymerization to produce high value-added chemicals, bio-oils, aromatics, or simply as a fuel [20]. In the latter case, the challenge is often with the upstream process allowing the isolation of the lignin. Processes such as Kraft or soda pulping will generate a lignin bound with sulfur and containing large concentrations of water and inorganics, making its recovery very challenging. The presence of inorganics, sulfur and water can also be a significant challenge for the production of monomers or composites. Combustion is an easy solution to utilize lignin in a short-term perspective, however the different grades of fuel (based on the purity of the lignin for instance) significantly impact its market value.

Finally, the last challenge related to the utilization of lignocellulosic biomass as a source of sugar for biofuel production is the utilization of C5 sugars. These are often found in combination with C6 sugars in hemicelluloses. Generally, pentoses cannot be fermented to ethanol using classical yeasts such as Saccharomyces cerevisiae and require other yeasts such as Scheffersomyces stipitis, Candida shehatae, and Pachysolen tannophilus. These yeasts require micro-aerophilic conditions during fermentation [14]. Since hemicelluloses are readily available in lignocellulosic biomass, some processes/technologies aim to first hydrolyze the hemicellulose component in a pretreatment step, prior to having to attack the more recalcitrant cellulose structure [21]. Hemicellulose has also been considered for the production of value-added products such as xylitol through the reduction of the C5 carbonyl structure, or through selective oxidation to organic acids (such as lactic acid), or even through acidinduced dehydration towards furfural [22]. Pentose, although not easily assimilated by classical yeasts, remains a sugar source that can be utilized to produce lower-level products such as methane through biomethanation [23]. However, it would be difficult to motivate establishing a fully industrial setup only for the utilization of hemicellulose, and they should be combined with other sources or carbon residues in order to boost the nitrogen and phosphorus demand of the biomethane-producing microorganisms.

This work will present the Biorefinery Done Right concept, where all the carbon from lignocellulosic biomass is used to produce marketable energy products, including ethanol (from carbohydrates), pellets (from lignin) and biomethane (from lower quality lignin and C5). This concept, commercialized by RéSolve Énergie, aims at a minimal use of reactants, low operating temperature and simple technologies that should ease the challenges often associated with scaling up these approaches. Despite the fact that all the biomass-derived products would target the commodity market, this approach would allow for a straightforward implementation of $2 \mathrm{G}$ biorefineries, helping to answer the energy needs of many locations around the world. While securing the energy market represents an important first step, higher-value utilization of some of the compounds from lignocellulosic biomass are being considered by the company as future opportunities for research and development. 


\section{EXPERIMENTAL}

\subsection{Hydrolysis}

The lignocellulosic biomass hydrolysis was performed via the RéSolve patent pending process. Acquired bark was grinded before use. The saccharification was done via a two-step acid hydrolysis. The bark was mixed with a highly concentrated acid solution and decrystallized at room temperature. Subsequently, the biomass was post-hydrolyzed by diluting the acid concentration and increasing the temperature of the reactor above the boiling point of water.

After post-hydrolysis, the hydrolysate was separated from the solid lignin by vacuum filtration through a $1.5 \mu \mathrm{m}$ glass microfiber filter paper (VWR). The separated lignin was washed to a neutral $\mathrm{pH}$ and allowed to dry. The dry lignin was pelletized via a pelletizing extruder at various temperatures and compression ratios.

\subsection{Fermentations}

The carbohydrate broths were neutralized using $\mathrm{CaCO}_{3}$ to a $\mathrm{pH}$ of 5 and subsequently concentrated using a Rotavapor (Buchi, Switzerland) at $60^{\circ} \mathrm{C}$ before being subjected to fermentation assays using Saccharomyces cerevisiae yeast. The inoculum was prepared using $5 \mathrm{~g} / \mathrm{L}$ of Thermosacc Dry ${ }^{\circledR}$ Active Dry Yeast (Lallemand Biofuels \& Distilled Spirits, Canada) cultivated in yeast growth media (glucose $-100 \mathrm{~g} / \mathrm{L}$, urea $-1 \mathrm{~g} / \mathrm{L}$, yeast extract $-50 \mathrm{~g} / \mathrm{L}$, peptone $-10 \mathrm{~g} / \mathrm{L}$ and lactrol $-0.1 \mathrm{~g} / \mathrm{L}$ ) at $30{ }^{\circ} \mathrm{C}$ and at a $\mathrm{pH}$ of 5.2. The yeast cells were incubated at $30^{\circ} \mathrm{C}$ and $180 \mathrm{RPM}$ for a period of $5 \mathrm{~h}$ prior to inoculation. The fermentation experiments were performed in $50 \mathrm{~mL}$ serum vials using $20 \mathrm{~mL}$ of carbohydrate hydrolysate and $1 \mathrm{~mL}$ of yeast inoculum. A control fermentation run was employed using a synthetic fermentation media in order to model, in a controlled setting, a second-generation ethanol production process. The media was designed considering the most common composition in terms of monomeric sugar content of hemicellulosic solutions, thus containing: $18 \mathrm{~g} / \mathrm{L}-$ glucose, $18.67 \mathrm{~g} / \mathrm{L}$ - xylose, $46.67 \mathrm{~g} / \mathrm{L}$ - mannose, $9.33 \mathrm{~g} / \mathrm{L}$ - arabinose, $7.33 \mathrm{~g} / \mathrm{L}$ - galactose, $1 \mathrm{~g} / \mathrm{L}$ - urea, $15 \mathrm{~g} / \mathrm{L}$ - yeast extract, $10 \mathrm{~g} / \mathrm{L}$ - peptone, $0.1 \mathrm{~g} / \mathrm{L}$ - lactrol. After inoculation, the bottles were capped with rubber septum stoppers and aluminum rings and flushed with N2 for four minutes. Incubation was performed at $30^{\circ} \mathrm{C}$ and $140 \mathrm{RPM}$ for a period of $36 \mathrm{~h}$. All the fermentation assays were performed in triplicate.

\subsection{Biomethanation}

The anaerobic digestion runs were performed using the lesser-quality lignin stream, after a prior solubilization and pre-digestive treatment. Activated sludge, previously enriched with the addition of $10 \mathrm{~g} / \mathrm{L}$ glucose for $48 \mathrm{~h}$ at $37^{\circ} \mathrm{C}$ and $60 \mathrm{RPM}$, was used at a $1: 1$ (substrate:sludge) ratio in $100 \mathrm{~mL}$ serum vials. Each of these vials were supplemented with $1 \mathrm{~g}$ of activated carbon in order to provide additional support to the microbial biofilm. Glucose $(5 \mathrm{~g} / \mathrm{L})$ and ammonium chloride $(3 \mathrm{~g} / \mathrm{L})$ were supplemented in order to set a C:N ratio of 25 to the mixture. The chemical oxygen demand (COD) of the substrate-activated sludge mixture was thus fixed at $15 \mathrm{~g} / \mathrm{L}$. The $\mathrm{pH}$ was set to 8 and $0.5 \mathrm{~g}$ of sodium bicarbonate was added to maintain the microenvironment alkalinity prior to the anaerobic digestion tests. The bottles were capped with rubber septa stoppers and aluminum rings, and flushed with $\mathrm{N}_{2}$ for four 
minutes. Incubation was performed at $37^{\circ} \mathrm{C}$ and $60 \mathrm{RPM}$ for a period of 15 days. All the biomethanation assays were performed in triplicate.

\subsection{Analytical methods}

Quantification of pentoses and hexoses was made using a Dionex ICS-5000+ ion chromatography system equipped with a $\mathrm{KOH}$ eluent generator to ensure a proper eluent concentration. The system is composed of an analytical gradient pump, a thermostated AS-AP autosampler and an electrochemical detector. Stability of the signal was ensured by a $200 \mathrm{mM} \mathrm{KOH}$ post-injection with a Dionex GP 50 gradient pump. To this purpose, a Dionex CarboPac SA10-4 $\mu \mathrm{M}$ column set up in an oven at $45^{\circ} \mathrm{C}$ was used. Detection was made with an electrochemical detector operating at $30^{\circ} \mathrm{C}$. Elution was made with an aqueous mixture of potassium hydroxide ( $1 \mathrm{mM}$ for 12 minutes, $10 \mathrm{mM}$ for 5 minutes, $1 \mathrm{mM}$ for 1 minute) at $1.25 \mathrm{~mL} / \mathrm{min}$ flow and injection volume of $0.4 \mu \mathrm{L}$. The calibration curve ranging from $10 \mathrm{ppm}$ to $1000 \mathrm{ppm}$ was generated using the following standards: L-arabinose (99\%), fructose (99\%), glucose (99\%), mannose (99\%), rhamnose (99\%), sucrose $(99.5 \%)$ and xylose $(100 \%)$, which were purchased from Sigma-Aldrich.

Fermentation inhibitors (glycolic acid, lactic acid, formic acid, acetic acid, levulinic acid, 5-HMF and furfural) and the produced ethanol were quantified in the liquid phase using an Agilent 1100 series HPLC equipped with a G1362A Refractive Index Detector (temperature was set to $\left.40^{\circ} \mathrm{C}\right)$. An isocratic elution method $(2,5 \mathrm{mM})$ was performed. A G1313A Autosampler was used for the injection of $40 \mu \mathrm{L}$ sample. Additionally, a G1322A Degasser and a G1311A Quaternary Pump were employed. For the separation of organic compounds, a ROA-Organic Acid $\mathrm{H}^{+}(8 \%)$ analysis column was used. The temperature of the column was set at $65^{\circ} \mathrm{C}$ and the elution was performed by a $0.01 \mathrm{M} \mathrm{H}_{2} \mathrm{SO}_{4}$ solution with a $0.8 \mathrm{~mL} / \mathrm{min}$ constant flow. All components were purchased from Agilent Technologies Inc., USA. The calibration curve ranging from $10 \mathrm{ppm}$ to $1000 \mathrm{ppm}$ were generated using the following standards: L-lactic $99 \%$ (Alfa Aesar), formic acid 100\% (Fisher Scientific), acetic acid 99.9\% (Aldrich), levulinic acid 99\% (Aldrich), glycolic acid 99\% (Aldrich), furfural 99\% (Aldrich), 5-hydroxymethyl furfural 99\% (Aldrich), levulinic acid 99\% (Aldrich) and glycolic acid 99\% (Aldrich).

In order to measure methane production yields, carbon dioxide $\left(\mathrm{CO}_{2}\right)$ present in the produced biogas was trapped in $3 \mathrm{M}$ solution of sodium hydroxide $(\mathrm{NaOH})$ [24]. A graduated syringe placed at the outlet of the $\mathrm{NaOH}$ solution was used to measure the volume of methane $\left(\mathrm{CH}_{4}\right)$ by water displacement. Cumulative methane yields were calculated by summing the amount of methane produced during the incubation period.

\section{RESULTS AND DISCUSSIONS}

The general block diagram of the RéSolve process is depicted in Fig. 1, below. In this scheme, the concept would be to use lignocellulosic residues coming from both forest and agricultural exploitation. Through a hub and spoke approach, the sugars and pellets (lignin) would be produced locally at the different industrial sites while the sugars would be sent to a central location for the fermentation and distillation steps, which are well known and established in the industry although still reliant on an economy of scale. The production of sugars and pellets is directly related to the RéSolve process, which can be operated at a smaller scale, hence allowing for the production of sugars in many locations linked to a central biorefinery.

The sugars produced from the RéSolve process will be determined by the original composition of the biomass. Hence the composition of C5 will vary depending on the amount and 


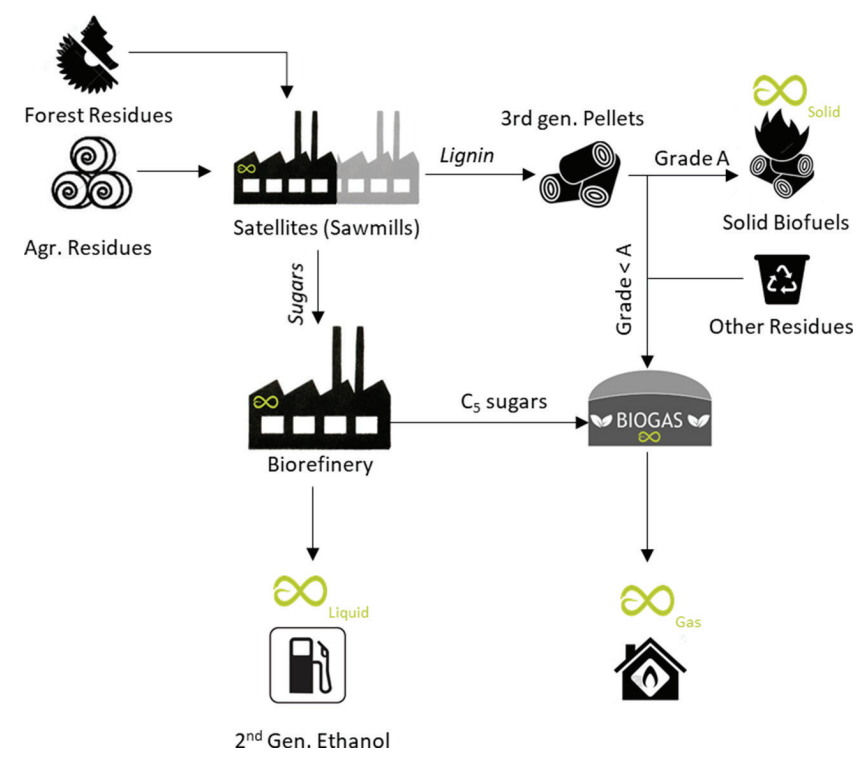

Figure 1: Block diagram for the Biorefinery Done Right commercialized by RéSolve Energie.

composition of the hemicellulose. For example, composition of different residual lignocellulosic biomass is presented in Table 1 . The results show clearly that some biomass contains more carbohydrate, which in turn is beneficial for the production of ethanol according to a biorefinery pathway. However, the price of biomass is also crucial for the overall economy of the process and while white wood chips will cost in the range of CAD 45-70 per tonne, other feedstock such as bark will often be cheaper, with a price varying from CAD 0-10 per tonne for piled softwood bark.

The RéSolve process allows conversion of up to $90 \%$ of the constitutive (cellulosic) sugar into free monomeric sugars with a minimal concentration of inhibitors. Hemicellulose, due to its more ramified and non-crystalline structure, is always easier to hydrolyze as compared to cellulose, and hence it could be considered that a $100 \%$ of the latter will be recovered in

Table 1: General composition of different residual biomass available in large quantities in North America

\begin{tabular}{lccc}
\hline $\begin{array}{l}\text { Chemical } \\
\text { composition }\end{array}$ & $\begin{array}{c}\text { Softwood bark } \\
{[\mathbf{w t} \%]}\end{array}$ & Poplar wood [wt\%] & Corn stover [wt \%] \\
\hline Extractives & $16.29 \pm 2.34$ & $11.66 \pm 0.73$ & $5.80 \pm 0.58$ \\
Moisture rate & $3.34 \pm 0.34$ & $5.02 \pm 0.75$ & $6.52 \pm 0.54$ \\
Ash & $2.16 \pm 0.02$ & $2.38 \pm 0.25$ & $2.02 \pm 0.06$ \\
Lignin & $28.01 \pm 0.74$ & $21.00 \pm 0.78$ & $15.33 \pm 0.63$ \\
$\alpha$-Cellulose & $34.18 \pm 1.91$ & $29.24 \pm 0.90$ & $38.02 \pm 1.96$ \\
Hemicelluloses & $20.15 \pm 2.63$ & $38.05 \pm 3.14$ & $37.27 \pm 0.09$ \\
Total & $98.63 \pm 4.07$ & $99.5 \pm 3.44$ & $96.41 \pm 2.21$ \\
\hline
\end{tabular}


the mixture. The conversion of cellulose or hemicellulose to glucose involves the addition of one molecule of water per hydrolyzed link and hence it is estimated that approximately 1.1 times the mass of anhydrous cellulose in addition to hemicellulose will be recovered as glucose and other free sugars following the hydrolysis.

Once hydrolyzed to their monomeric forms, most of the C6 carbohydrates will be suitable for fermentation. Fermentation results using sugars obtained from bark biomass via the RéSolve process show that in most cases, progression of the fermentation was comparable to the reference which was composed of C5 and C6 sugars. Slight variations in the hydrolysis process such as the inclusion of a decrystallization step and two different concentrations of the obtained carbohydrates, were employed in order to determine their impact on the subsequent fermentation steps (Fig. 2). The samples resulted in the complete conversion of C6 monomers to ethanol in the first $24 \mathrm{~h}$ of fermentation. Moreover, not including the additional decrystallization step led to the conversion of these monomers in the first $12 \mathrm{~h}$, as in the case of the synthetic fermentation media. These observations support the claim that the $\mathrm{C} 6$ sugars produced from the fermentation of the carbohydrate through the RéSolve process were suitable for ethanol production.

The remaining C5 fraction and fermentation broth have been previously reported by Boboescu et al. as a good substrate for the production of microalgae showing, to a certain extent, that such feedstock had all the required elements to sustain biomass growth [26]. Moreover, these fermentation effluents obtained from mixtures of lignocellulosic carbohydrates hold residual C5 carbohydrates, which could supplement subsequent biomethane production processes. However, these residual carbohydrate streams may not by themselves justify an industrial scale biomethanation system, and the biogas production plant would need to be supplied with other sources of carbon as well as sources of nitrogen and phosphorus. In North America (more specifically Canada) the occurrence of large volumes of lignocellulosic biomass does not necessarily correspond with large populations [27], [28]. In this sense, table wastes, known for their potential for the production of biogas [29], cannot be sourced in high
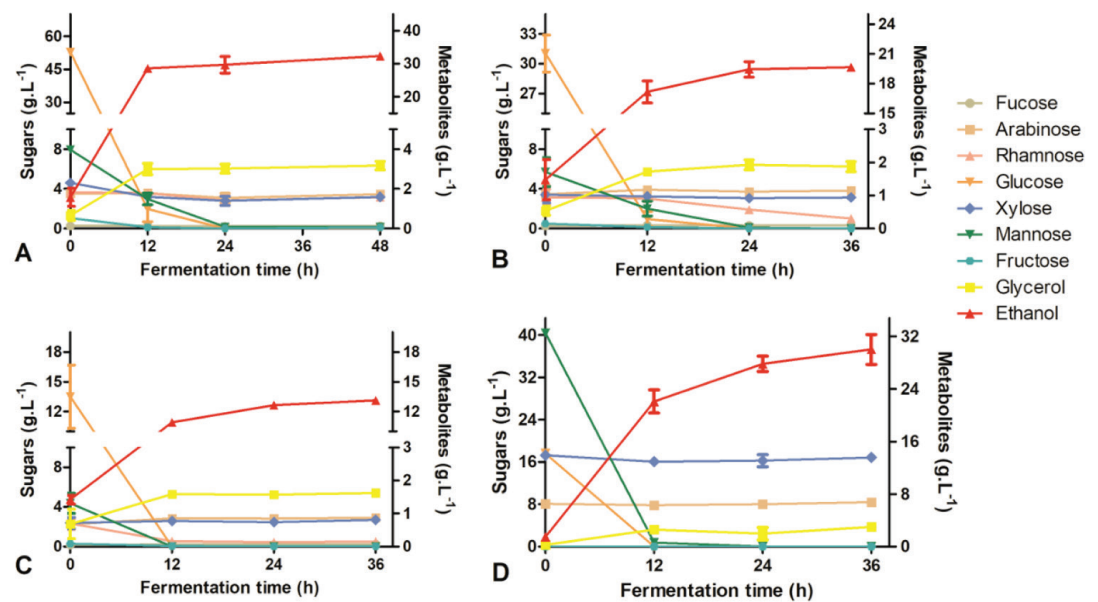

Figure 2: Fermentation behavior of carbohydrates produced from bark biomass using the RéSolve process as compared to a synthetic media containing mixed pentoses and hexoses. A: diluted hydrolysate including the decrystallization step at high initial concentration; B: diluted hydrolysate including the decrystallization step at low initial concentration; C: hydrolysate without the decrystallization step; D: synthetic media. 
enough amounts to act as a sufficient additive to the hemicellulose produced by an average scale biorefinery. Agricultural biomass does, however, coincide with other farm by-products (such as manure), and could eventually be combined to a hemicellulosic stream for production of biogas. Finally, geographical locations where forest biomass (and its residues) are available in large quantities may not offer other sources of carbon as well as other elements required for the production of biogas. However, using the RéSolve process, other residual streams such as lignin could be used as a carbon feedstock for the production of biogas. Utilizing lignin for biogas generation would result in lesser production of pellets (vide infra), but in a situation where the pellets would have higher concentrations of inorganics (ashes) as well as sulfur and/ or chlorine, purification of the lignin might be more expensive than the overall price of pellets. Hence the interest for using this as an additional carbon source for the production of biogas.

The last part of this 'puzzle' is lignin, which is a research focus for many groups working in the utilization of biomass in a biorefinery approach [30], [31]. Lignin has often been considered the main technological challenge related to large scale implementation of biorefineries. Using the RéSolve process, lignin is recovered as close to 'native' as possible since the process attacks the carbohydrates under acidic conditions. The remaining lignin results being separated from the carbohydrate macromolecules, but will not be altered significantly, as would be the case when utilizing Kraft or soda pulping. Since lignin is recovered as fine particles (see Fig. 3), it tends not to sequester a large portion of the inorganics that may originally occur in the raw biomass. The HHV for dried samples obtained when the RéSolve process was applied to different types of lignocellulosic residues is presented in Table 2, along with a comparison to the original biomass from which it was extracted

As reported in Table 2, the heating value of the different lignin extracted from residual biomass overall shows a higher calorific value as compared to raw biomass, which can be related to the fact that the more oxidized structures (carbohydrates) have been removed from the lignocellulosic matrix, leaving behind the lignin macromolecules with a significantly lower
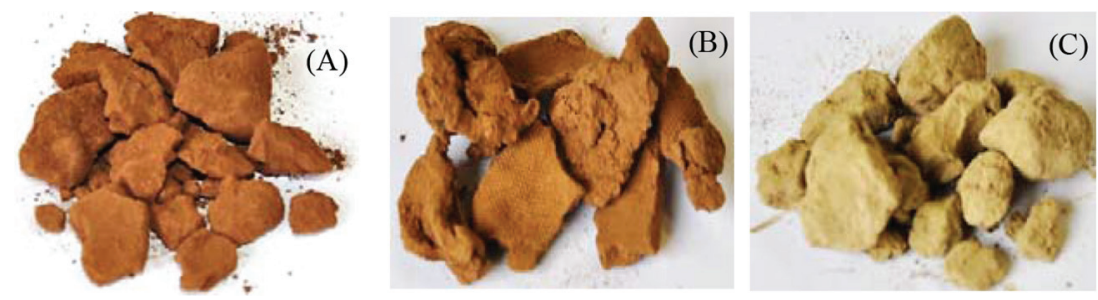

Figure 3: Example of lignin particles recovered following the RéSolve process from (A) softwood bark, (B) poplar wood and (C) corn stover.

Table 2: Higher heating value monitored from different dry lignin obtained from the RéSolve process.

\section{Calorific value [GJ/tonne]}

\begin{tabular}{lcc} 
Biomass & Lignin pellets & $\begin{array}{c}\text { Raw biomass (in powder } \\
\text { form) }\end{array}$ \\
\hline Poplar wood & $25.36 \pm 0.27$ & $19.26 \pm 0.47$ \\
Corn stover & $20.09 \pm \mathrm{n} / \mathrm{a}$ & $18.34 \pm 0.21$ \\
Softwood bark & $25.97 \pm 0.23$ & $20.30 \pm 0.1$ \\
\hline
\end{tabular}


oxygen content due to its aromatic structure. Since it has been reported that lignin can be used in pelleting to increase the bonding of the particles [32], and that it has an overall heating value higher than first (17-19 GJ/tonne) or second generation (20-22 GJ/tonne) pellets, the production of pellets entirely composed of lignin could be classified as 'third generation' solid fuel.

In some cases (such as poplar), the heating value of 3rd generation pellets would be amongst the highest reported, at the lower limit of the heating value found in petroleum coke (32.6 GJ/tonne) [33]. Handling this material, however, is different from classical firstgeneration wood pellets, as well as second-generation torrefied pellets. Nevertheless, our preliminary results demonstrate that the pellets have a darker color (see Fig. 4). Some developments are still needed to improve some properties of the pellets regarding the initial moisture content, temperature during the pelletization process and compression rate determined by the die geometry. For example, the Figure 4 shows the difference between pellets made from softwood bark lignin with a compression ratio of 3 and 6 .

Even though solid biofuel remains a suitable starting alternative for the utilization of lignin, other value-added applications could eventually be considered to get more value out of this abundant source of natural aromatics. In open literature, different potential utilizations have been reported for lignin such as for the production of high value monomers, for the production of plastics and composites as well as in the formulation of adhesives [20]. However, depending on the condition of the original biomass, some lignin may contain very high levels of ashes such as bark and corn stover lignin (Table 2), even after passing through the RéSolve process. In this case, two options could be considered. The first would be to use these pellets as a low-grade fuel. The other option would be to purify the pellets by removing the inorganic and/or other elements that prevent these pellets from being classified as Grade A. The latter option could be a favorable one for biomass such as softwood bark. In cases such as corn stover lignin, conversion into biogas could represent a better opportunity to take advantage of this renewable carbon source, while still targeting the commodities markets.

Conversion of lignocellulosic biomass to methane has been thoroughly investigated in open literature, especially during the last decade where the biogas industry showed significant expansion globally [34]. Numerous approaches have been considered in order to produce methane, either relying on thermochemical processes such as gasification [35] or pyrolysis [36], or even biological processes. In the latter, biomass is pretreated with microorganisms [23] or enzymes [37] to generate a substrate that could be digested by methane producing microorganisms more easily. RéSolve Énergie has also investigated a complementary approach allowing the production of biogas from lignin. However, the research pursuing
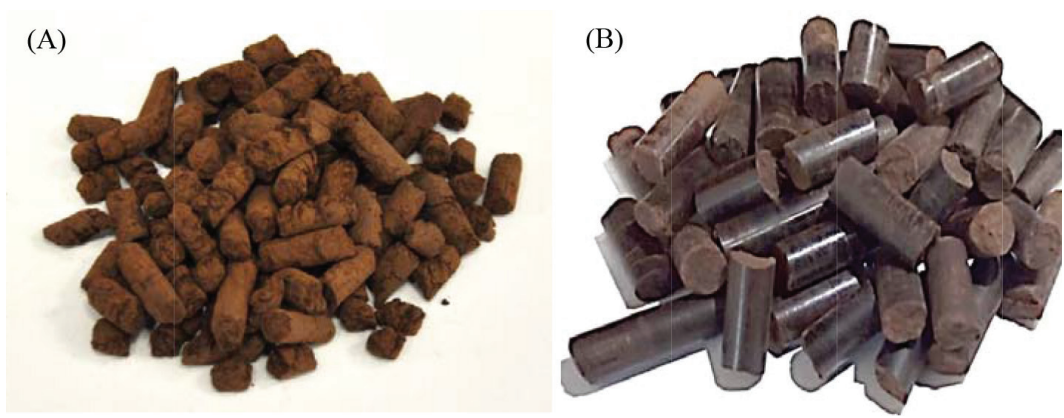

Figure 4: Example of 3rd generation lignin produced using the RéSolve process applied on bark with a compression ratio of (A) 3, and (B) 6 . 

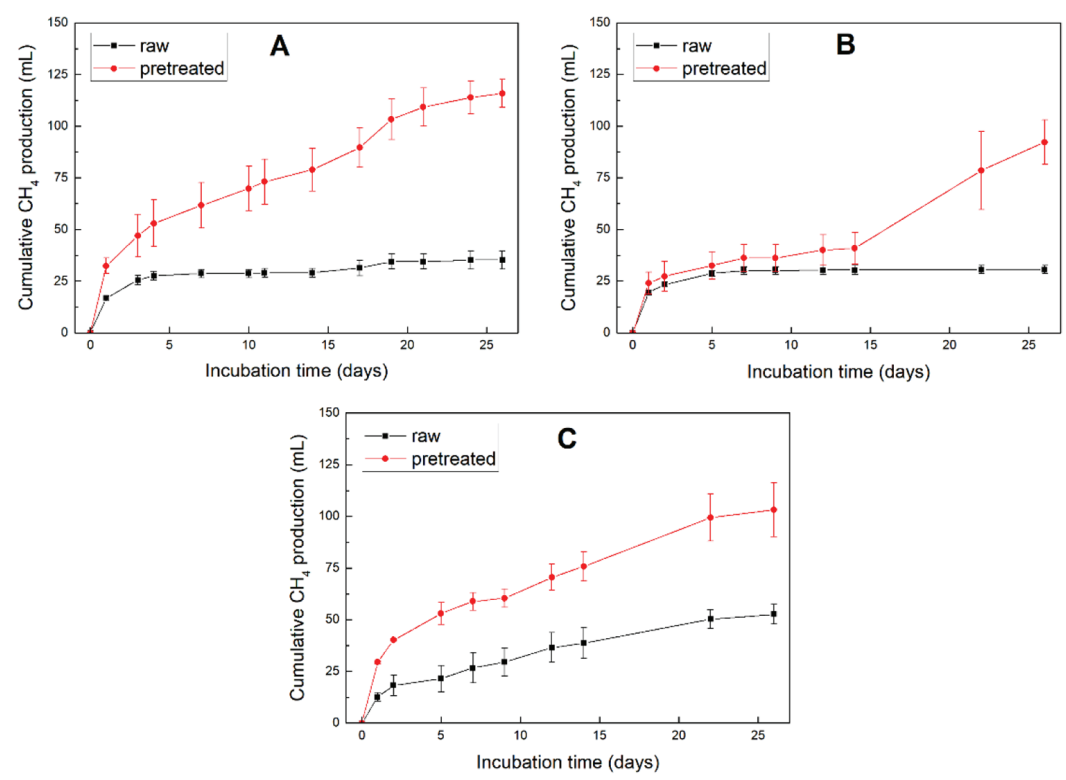

Figure 5: Behavior of pre-digested lignin as compared to the raw lignin obtained from the RéSolve process for the production of biogas. (A) corn lignin, (B) bark lignin, (C) poplar lignin.

these avenues is very limited [38]-[40]. In order to validate the concept, lignin generated from the RéSolve process using different types of biomass were pre-treated, digested and converted to biomethane through a classical biological approach (Fig. 5). The obtained results show variations in the methane-production potential, based on the different sources of lignin used. However, in most cases, the lignin samples, which were not initially pretreated generated limited or no methane. Thus, preliminary treatment of the macromolecule allowed for the substrate to be significantly more receptive to conversion into biogas.

\section{CONCLUSION}

This work depicted an example of how the use of lignocellulosic biomass could be optimized for the direct production of three marketable products, a liquid (cellulosic ethanol), a solid (3rd generation pellets) and a gas (biomethane). The Biorefinery Done Right concept, a feedstock agnostic process, allows for a complete utilization of the carbon content found in different biomass feedstocks, including more recalcitrant tissues (such as bark) that were never previously considered, at least for the production of cellulosic ethanol. Although the production of ethanol, pellets and biogas may not be the optimal potential use of the different parts of the lignocellulosic substrate, it is still a very promising and efficient first step. It would allow to reach economically viable levels more rapidly and can hence be the basis for the deployment of the cellulosic ethanol industry. This work also reports on an efficient method allowing the pre-digestion of the lignin macromolecule in order to make it suitable as a feedstock for a classical biomethane production process.

\section{ACKNOWLEDGEMENTS}

The authors would like to acknowledge the participation of RéSolve Énergie to this project as well as the CRIBIQ, MITACS and NSERC who contributed in funding this work. 


\section{REFERENCES}

[1] "The Paris Agreement | UNFCCC," 2019. [Online]. Available: https://unfccc.int/ process\#:a0659cbd-3b30-4c05-a4f9-268f16e5dd6b (accessed 17 May 2019).

[2] Dutta, K., Daverey, A. \& Lin, J.G., Evolution retrospective for alternative fuels: First to fourth generation. Renewable Energy, 69, pp. 114-122, September 2014. https://doi. org/10.1016/j.renene.2014.02.044

[3] Lee, R.A. \& Lavoie, J.M., From first- to third-generation biofuels: Challenges of producing a commodity from a biomass of increasing complexity. Animal Frontiers, 3(2), pp. 6-11, April 2013. https://doi.org/10.2527/af.2013-0010

[4] Chavez-Rodriguez, M.F. \& Nebra, S.A., Assessing GHG emissions, ecological footprint, and water linkage for different fuels. Environmental Science \& Technology, 44(24), pp. 9252-9257, December 2010. https://doi.org/10.1021/es101187h

[5] Edenhofer, O., Pichs-Madruga, R., Sokona, Y., Farahani, E., Kadner, S., Seyboth, K., ... \& Kriemann, B., OIPCC, 2014: Summary for policymakers. In: climate change 2014, Mitigation of Climate Change. In Contribution of Working Group iii to the Fifth Assessment Report of the Intergovernmental Panel on Climate Change. New York, 2014.

[6] IRENA, Renewable Power Generation Costs in 2017. Abu Dhabi, 2018.

[7] McMahon, J., The 4 lingering obstacles to electric vehicle adoption (and what might overcome them). Forbes, 27 January 2019.

[8] Lund, J., One size doesn't fit all: How commercial EVs present unique challenges for charging infrastructure | GreenBiz. GreenBiz, 11 April 2019.

[9] Obernberger, I., Carlsen, H. \& Biedermann, F., State-of-the-art adn future developments regarding small-scale biomass CHP systems with a special focus on ORC and Stirling engine technologies. In International Nordic Bioenergy, 2003.

[10] Walker, G.M., 125th anniversary review: Fuel alcohol: Current production and future challenges. Journal of the Institute of Brewing, 117(1), pp. 3-22, January, 2011. https:// doi.org/10.1002/j.2050-0416.2011.tb00438.x

[11] Lennartsson, P.R., Erlandsson, P. \& Taherzadeh, M.J., Integration of the first and second generation bioethanol processes and the importance of by-products. Bioresource Technology, 165, pp. 3-8, August 2014. https://doi.org/10.1016/j.biortech. 2014.01.127

[12] Jönsson, L.J. \& Martín, C., Pretreatment of lignocellulose: Formation of inhibitory by-products and strategies for minimizing their effects. Bioresource Technology, 199, pp. 103-112, January 2016. https://doi.org/10.1016/j.biortech.2015.10.009

[13] Sun, Y. \& Cheng, J., Hydrolysis of lignocellulosic materials for ethanol production: a review. Bioresource Technology, 83(1), pp. 1-11, May 2002. https://doi.org/10.1016/ s0960-8524(01)00212-7

[14] Branco, R., Serafim, L., Xavier, A., Branco, R.H.R., Serafim, L.S. \& Xavier, A.M.R.B., Second generation bioethanol production: On the use of pulp and paper industry wastes as feedstock. Fermentation, 5(1), p. 4, December 2018. https://doi.org/10.3390/fermentation5010004

[15] Galbe, M. \& Zacchi, G., A review of the production of ethanol from softwood. Applied Microbiology and Biotechnology, 59(6), pp. 618-628, September 2002. https://doi. org/10.1007/s00253-002-1058-9

[16] Shrotri, A., Kobayashi, H. \& Fukuoka, A., cellulose depolymerization over heterogeneous catalysts. Accounts of Chemical Research, 51(3), pp. 761-768, March, 2018. https://doi.org/10.1021/acs.accounts.7b00614 
[17] Irmer, J., Lignin - a natural resource with huge potential - Bioeconomy. BioEkonomie, 2017. [Online]. Available at https://www.biooekonomie-bw.de/en/articles/dossiers/lignin-a-natural-resource-with-huge-potential/ (Accessed 18 May, 2019).

[18] Zhao, X.Q. et al., Bioethanol from Lignocellulosic Biomass. Springer, Berlin, Heidelberg, 2011, pp. 25-51.

[19] Ruiz-Dueñas, F.J. \& Martínez, Á.T., Microbial degradation of lignin: how a bulky recalcitrant polymer is efficiently recycled in nature and how we can take advantage of this. Microbial Biotechnology, 2(2), pp. 164-177, March 2009. https://doi.org/10.1111/ j.1751-7915.2008.00078.x

[20] Ponnusamy, V.K., Nguyen, D.D., Dharmaraja, J., Shobana, S., Banu, R., Saratale, R.G., ... \& Kumar, G., A review on lignin structure, pretreatments, fermentation reactions and biorefinery potential. Bioresource Technology, 271, pp. 462-472, January 2019. https:// doi.org/10.1016/j.biortech.2018.09.070

[21] Wyman, C.E., Biomass ethanol: Technical progress, opportunities, and commercial challenges. Annual Review of Energy and the Environment, 24(1), pp. 189-226, November 1999. https://doi.org/10.1146/annurev.energy.24.1.189

[22] Verardi, A., De Bari, I., Ricca, E. \& Calabrò, V., Hydrolysis of lignocellulosic biomass: Current status of processes and technologies and future perspectives. Bioethanol, February 2012. https://doi.org/10.5772/23987

[23] Pattnaik, R. \& Mishra, S., Microbial pretreatment of lignocellulosic biomass for enhanced biomethanation and waste management. Biotech, 8(11), p. 458, 2018. https:// doi.org/10.1007/s13205-018-1480-z

[24] Siddiqui, Z., Horan, N.J. \& Anaman, K., Optimisation of c:n ratio for co-digested processed industrial food waste and sewage sludge using the bmp test. International Journal of Chemical Reactor Engineering, 9(1), January 2011. https://doi.org/10.1515/15426580.2327

[25] Boboescu, I.Z., Beigbeder, J.B., Damay, J., Duret, X., Lalonde, O. \& Lavoie, J.M., Transitioning towards a circular economy in Quebec: An integrated process for first-, second- and third-generation ethanol from sweet sorghum and Chlorella vulgaris biomass. Industrial Biotechnology, 15(3), pp. 160-178, 2019. https://doi.org/10.1089/ ind.2019.0010

[26] Milbrandt, A., A geographic perspective on the current biomass resource availability in the United States. NREL Tech. Report no, pp. 1-50, December, 2005. https://doi. org/10.2172/861485

[27] NRCan., Interactive maps | Natural resources Canada. [Online], available https://www. nrcan.gc.ca/earth-sciences/geography/atlas-canada/interactive-maps/18234 2019. (accessed 23 May 2019).

[28] Kuo, J. \& Dow, J., Biogas production from anaerobic digestion of food waste and relevant air quality implications. Journal of the Air \& Waste Management Association, 67(9), pp. 1000-1011, September 2017.

[29] Ragauskas, A.J. et al., Lignin valorization: Improving lignin processing in the biorefinery. Science, 344(6185), pp. 1246843-1246843, May 2014.

[30] Xu, Z., Lei, P., Zhai, R., Wen, Z. \& Jin, M., Recent advances in lignin valorization with bacterial cultures: Microorganisms, metabolic pathways, and bio-products. Biotechnology for Biofuels, 12(1), p. 32, December 2019. 
[31] Kuokkanen, M., Vilppo, T., Kuokkanen, T., Stoor, T. \& Niinimäki, J., Additives in wood pellet production - A pilot-scale study of binding agent usage. BioResources, 6(4), pp. 4331-4355, November 2011.

[32] Jayaraman, K. \& Gokalp, I., Gasification characteristics of petcoke and coal blended petcoke using thermogravimetry and mass spectrometry analysis. Applied Thermal Engineering, 80, pp. 10-19, April 2015. https://doi.org/10.1016/j.applthermaleng.2015.01.026

[33] Scarlat, N., Dallemand, J.F. \& Fahl, F., Biogas: Developments and perspectives in Europe. Renewable Energy, 129, pp. 457-472, December 2018. https://doi. org/10.1016/j.renene.2018.03.006

[34] Wilkie, A.C., Biomethane from biomass, biowaste, and biofuels. In Bioenergy, American Society of Microbiology, 2008, pp. 195-205. https://doi.org/10.1128/9781555815547.ch16

[35] Wang, A., Austin, D. \& Song, H., Investigations of thermochemical upgrading of biomass and its model compounds: Opportunities for methane utilization. Fuel, 246, pp. 443-453, 2019. https://doi.org/10.1016/j.fuel.2019.03.015

[36] Lin Yunqin, L., Wang Dehan, W. \& Wang Lishang, W., Biological pretreatment enhances biogas production in the anaerobic digestion of pulp and paper sludge. Waste Management \& Research, 28(9), pp. 800-810, September 2010. https://doi. org/10.1177/0734242x09358734

[37] You, Z. et al., Effects of corn stover pretreated with $\mathrm{NaOH}$ and $\mathrm{CaO}$ on anaerobic codigestion of swine manure and corn stover. Applied Sciences, 9(1), p. 123, December 2018. https://doi.org/10.3390/app9010123

[38] Adarme, O.F.H., Baêta, B.E.L., Lima, D.R.S., Gurgel, L.V.A. \& de Aquino, S.F., Methane and hydrogen production from anaerobic digestion of soluble fraction obtained by sugarcane bagasse ozonation. Industrial Crops and Products, 109, pp. 288-299, December 2017. https://doi.org/10.1016/j.indcrop.2017.08.040

[39] Ahring, B.K., Biswas, R., Ahamed, A., Teller, P.J. \& Uellendahl, H., Making lignin accessible for anaerobic digestion by wet-explosion pretreatment. Bioresource Technology, 175, pp. 182-188, January 2015. https://doi.org/10.1016/j.biortech.2014.10.082 